\title{
Policies and Procedures in Providing Competent Customer Service in Urgent Care Centers
}

\author{
Marcus Caster \\ Walden University, Minneapolis, USA \\ Email: marcuscaster@yahoo.com
}

How to cite this paper: Caster, M. (2020). Policies and Procedures in Providing Competent Customer Service in Urgent Care Centers. Open Journal of Business and Management, 8, 1164-1192.

https://doi.org/10.4236/ojbm.2020.83075

Received: February 2, 2020

Accepted: May 16, 2020

Published: May 19, 2020

Copyright (๑) 2020 by author(s) and Scientific Research Publishing Inc. This work is licensed under the Creative Commons Attribution International License (CC BY 4.0).

http://creativecommons.org/licenses/by/4.0/

\section{(c) (i) Open Access}

\begin{abstract}
The purpose of this case study was to explore customer care strategies that managers of urgent care businesses used to improve customer care services and patient satisfaction. The target population consisted of 1 urgent care manager from 3 separate urgent care clinics with the highest customer satisfaction ratings in Alabama. Semistructured interviews and patient survey forms were the data sources. Data were analyzed using thematic analysis, which identified similar codes, patterns, and themes. The 3 primary themes that emerged from the thematic analysis were patient-focused care, social media outreach, and employee engagement. Participants in the study indicated the importance of placing the needs of the patients first. In addition, the participants shared the motto that the customer is always right. The findings from the participants confirm that patient focused care increases patient satisfaction. Each participant expressed they had true loyal customers that spread their satisfaction experience about their clinic to other members of the community. Findings in the study supported the efforts of the UCMs' strategies on improving customer care services and patient satisfaction. The findings of this study may be of value to business managers in terms of how UCMs can provide customer care services to improve patient satisfaction.
\end{abstract}

\section{Keywords}

Business Sustainability, Customer Care, Patient Satisfaction, Urgent Care Centers

\section{Introduction and Background}

The clinical staffs of UCMs are responsible for providing high-quality care to ensure patient satisfaction. Dissatisfied patients reduce financial stability in HC 
facilities (Ferrand et al., 2016). Therefore, patient satisfaction is of interest to business managers and owners in the HC industry. I explored a customer care service business problem that UCMs encounter when trying to improve patient satisfaction. Patient dissatisfaction with urgent care clinics (UCCs) can increase the need for better customer care services for patients demanding satisfaction from UCCs in the health care (HC) industry. With increasing patient expectations, this burden raised the demand for better community-based health care facilities (Loewenson \& Simpson, 2017). Managers of UCCs claimed that a third of customers that visited their HC facility were unhappy when receiving care (Mercieca, Cassar, \& Borg, 2014). Moreover, some business leaders lacked the knowledge to sustain financial performance in the HC industry. Business leaders in the HC industry compete in branding and marketing for sustainability, while improved customer services remain essential to the extension of a business brand (Askariazad \& Babakhani, 2015). Competition is high in HC facilities, and leaders understand that patients are demanding satisfactory customer care services (Pflueger, 2016). According to Pflueger (2016), the two measures managers place on HC are: 1) patient care, and 2) quality of customer care. Business managers that redirect their organizational focus to marketing and branding, as opposed to customer satisfaction, may lack knowledge on improving patient satisfaction. Therefore, I explored customer care strategies that UCMs use to provide a positive experience that may contribute to the improvement of patient satisfaction in the HC industry. The qualitative research study method was appropriate for the research question, which requires a thorough exploration of strategies managers used to improve customer care services and patient satisfaction. I used an embedded single case study design for this qualitative research study. To understand the complexity of a social phenomenon, researchers perform case studies (Merriam \& Tisdell, 2015; Stake, 2010; Yin, 2017).

\section{Problem Statement}

The financial stability of HCCs decreased because patients are dissatisfied with services (Ferrand et al., 2016). Some healthcare managers (HCMs) reported that $71 \%$ of patients are dissatisfied with emergency room (ER), urgent, and traditional physician care (Mercieca et al., 2014). The general business problem was that some urgent care leaders experience financial risks when implementing new customer care strategies, with no guarantee of success in improving patient satisfaction. The specific business problem was that some UCMs lack customer care strategies to improve patient satisfaction.

\section{Purpose Statement}

The purpose of this qualitative embedded single case study was to explore customer care strategies UCMs used to improve patient satisfaction. The target population consisted of three UCMs within one HCC organization, with less than 500 employees located in Alabama that improved the quality of patient satisfaction. The study results may contribute to positive social change by helping UCMs provide a higher quality of customer care services, which could benefit 
local communities by decreasing illnesses and improving patient satisfaction in HCCs.

\section{Research Question}

The Central Research Question Guiding this study was: What customer care strategies do UCMs use to improve patient satisfaction? I collected data using semistructured face-to-face interviews with open-ended questioning. I also used archival company internet survey forms from UCCs websites that gave patients an opportunity to rate their physician and visit.

\section{Assumptions, Limitations, and Delimitations \\ Assumptions}

Assumptions include unsubstantiated statements or facts that researchers use to validate a research study. Leedy and Ormrod (2013) stated assumptions were research facts that may be true and accepted without verifying the information. I assumed that the participants would give honest and factual responses. I met the assumption by creating a relaxing environment that made the participants feel comfortable to answer questions openly and honestly. A second assumption was the inclusion and criteria selection of the participants. I assumed by including UCMs that they would have the knowledge and experience to answer the interview questions and help in the findings of the overarching research question. The final assumption was assuming that a qualitative embedded single case study was the appropriate approach for answering the overarching research question. Future researchers can expand on the study by using strategies to support increased customer loyalty and improve patient satisfaction.

\section{Limitations}

The limitations of a study related to occurrences out of control of the researcher. The limitation may affect the results or conclusions of the study. Limitations are the uncontrollable boundaries and constraints that have a direct influence on research results (Brutus, Aguinis, \& Wassmer, 2012). The first limitation involved using the qualitative method for research. When a researcher selects certain methodologies and designs, they accept inherent limitations over which he or she may have little control (Simon \& Goes, 2013). Certain methodologies and designs may limit the researcher in terms of control and collecting viable data (Simon \& Goes, 2013). I accepted that I might encounter inherent limitations by selecting the qualitative method because qualitative research occurs in a natural setting and relates to a specific phenomenon. Another limitation was using a single case study design to explore customer care strategies UCMs used to improve the quality of patient satisfaction. The purpose of this single case study was to explore the customer care strategies of three UCMs. The results may not reflect similar results of other UCCs.

\section{Delimitations}

Delimitations are objectives that bound the scope and set restrictions for research studies (Leedy \& Ormrod, 2013). The first delimitation was only exploring three UCMs in the same organization and geographical region. The second 
delimitation was using purposeful selection. Purposeful selection is nontransferable to a larger scope (Marais, 2012). The third delimitation involved requesting archival company internet survey results. The final delimitation is that I only explored customer care strategies UCMs used to improve patient satisfaction. Excluded in the study are other business strategies UCMs may use in business that is not directly relevant to the purpose of this study. Future researchers may expand on this topic by having a larger sample size, perform multiple case studies, and explore employee satisfaction rather than patient satisfaction.

\section{Significance of the Study}

\section{Contribution to Business Practice}

The findings of this study may be of value to business managers in terms of how UCMs can provide customer care services to improve patient satisfaction. Managers using successful guidelines associated with sustainability can retain their current customers, which increases repeat business (Srivastava \& Rai, 2014). UCMs may experience higher quality performance and efficiency in UCCs by increasing customer loyalty. Acknowledging the importance of patient perceptions in HC supports a positive customer care environment and may foster economic growth and stability (Al-Abri \& Al-Balushi, 2014). The improvement of customer care services can enhance business sustainability in UCCs. Some HCMs noticed the value of considering the patient's customer care perception and started incorporating patient-centered care in their mission statements (Al-Abri \& Al-Balushi, 2014). Practicing good strategies for improving patient satisfaction may have positive implications on social change.

\section{Implications for Social Change}

The study results may contribute to positive social change by helping UCMs provide a higher quality of customer care services, which could benefit local communities by decreasing illnesses and improving patient satisfaction in HCCs. Patient satisfaction is a major concern for HCMs in Alabama and members of the local community. Beausejour et al. (2015) stated that the inclusion of HCCs in communities helps develop relations and bridges the gap between management and community members. By increasing the quality of customer care services, the findings of the study may result in more patient satisfaction and provide positive engagement from members of the local community. Collaboration between $\mathrm{HC}$ officials and community stakeholders advances population health and increases developmental activities (Carlton \& Singh, 2018). Therefore, the implication of positive social change for UCC community members could lead to higher quality inpatient care and overall higher quality of health for people in these communities. A potential increase in overall patient satisfaction could result in healthier people.

\section{A Review of the Academic Literature}

\section{Customer Loyalty Theory}

The customer care model that explores cognitive customer behavior and atti- 
tudes to improve marketing strategies is CLT. Dick and Basu (1994) introduced the customer loyalty two-dimensional system, which identifies customer behavior and attitudes. Business leaders analyze the two-dimensional system to develop marketing and customer care strategies for retaining customer loyalty and improving satisfaction. Managers have an enormous challenge in order to gain loyalty from customers. Customer loyalty is complex, and a direct reflection of the atmosphere formulated by the customer (Babin, Boles, \& Griffin, 2015). Maintaining customer satisfaction requires the knowledge to persuade customers to become loyal. The CLT, often referred to as brand loyalty theory, provided the analytics of conceptualization in this study. Moreover, exploring the behavior and attitude components of CLT can affect customer care and customer satisfaction by providing a model to improve customer loyalty. Kotler (2015) argued that the cost to interest new customers is far greater than retaining current customers. Kotler noted five tenets to customer loyalty: 1) attaining current customers to reach new customers, 2) existing customers tend to patronage more, 3) regular customers are more predictable in their services, which is less expensive, 4) existing satisfied customers is free marketing, and 5) existing customers are prone to pay prices at a premium. The tenets by Kotler support methods UCMs can use to improve customer care strategies and patient satisfaction.

\section{HC Services}

Patients are seeking lower costs and better health care services from frontline employees. The quality of customer care service is on the decline, while the cost is increasing (Wells, Semple, \& Lane, 2015). Stock and Bednarek (2014) wrote that customer demands happen at the service interface and include behaviors like hostility and complaining about frontline employees. Customers need emotional support, and they subtlety demand it during interactions with frontline employees Stock and Bednarek (2014). Cao, Jiang, and Wang (2016) wrote that structural relationships among customers and the influence factors researchers embrace consist of structural equation models. By reducing the adverse effect of data collected from the structural equation model, business owners can predict customer demand. Tracking customer behavior and showing organizational transparency builds relationships (Mehra, 2016). Lack of transparency and severed relationships may cause patients to become dissatisfied. The HC industry is competitive, and managers realize patients are demanding better quality care and services (Pflueger, 2016). Lokdam, Kristiansen, Handlos, and Norredam (2016) stated the importance of health care is increasing throughout borders because of globalization, and the mobility of patients. Of 44 countries in Europe, 18 of the countries implemented strategies to regulate health care quality (Prakash, 2015). In addition, the private sector controls over $83 \%$ of the HC facilities, which has a major impact on GNP (Prakash, 2015). Despite major overhauls in $\mathrm{HC}$, many customers are still confused between the quality of customer services and patient care.

HC Communication Barriers 
Proper communication in $\mathrm{HC}$ is conducive to the quality of customer care services provided to patients. Communication barriers can cause stress for patients when there is a lack of communication between HC workers and patients concerning procedures (Research Triangle Institute International, 2016). Common barriers that impede communication include: 1) mental health morbidity, 2) wait time, 3) ineffective strategies, and 4) unqualified employees. Some HC providers lack collaboration due to busy schedules and social support, which can cause mental health morbidity (MHM) (Eklof \& Ahlborg, 2016). According to Eklof and Ahlborg (2016), MHM is an acute psychological disorder often present in hospitals, which causes disorganization in HC staff teamwork. Also, Eklof and Ahlborg defined social support as having reliable feedback and support from an employee's supervisor. Often, MHM is a hidden diagnosis present in nurses and HC staff workers, which may cause resistance and communication problems that can influence patient satisfaction. UCMs that look for hidden MHM symptoms in their employees may intervene on issues that could prohibit their ability to improve customer care services.

Improving patient satisfaction is pivotal for HCCs. HCCs must communicate important medical information to the patient promptly. Patients that have to wait on extended communication regarding diagnosis become dissatisfied with their customer care services (Mehra, 2016). Dissatisfied patients are reluctant to communicate with their HC providers if they feel the providers neglect their needs because of a lack of communication (Platonova, Qu, \& Warren-Findlow, 2019). According to Mehra (2016), 33\% of patients that lack communication with their HC provider suffer increased effects and medical complications. Moreover, HCCs must research and develop more tools and strategies to alleviate any potential patient from being dissatisfied. UCMs that share medical information promptly and encourage effective communication can improve their efforts on patient satisfaction.

\section{Duties of HCMs}

HCMs play a vital role in managing customer care services to improve patient satisfaction. According to Holton and Grandy (2016), managers are responsible for maintaining and applying strategies to encourage their employees to complete specific tasks. In addition, HC facility owners place managers where they can be more effective for the organization (Oldenhof, Stoopendaal, \& Putters, 2016). HCMs should strengthen relations with staff members to enhance employee engagement. According to Davenport (2015), managers that establish a bond with their employees encourage a high performance of customer care services. Moreover, HCMs can recognize key factors that contribute to satisfactory employee performance and customer care services (Dainty \& Sinclair, 2016). Therefore, UCMs can learn to identify satisfactory employee performance to establish an environment that will satisfy their patients. The demand and expectations from HCCs and patients have increased the leadership role of HCMs. HCMs are required to implement training, resources, and innovative strategies 
to encourage employees to be more effective (Engle et al., 2017). High expectations should be the center dynamics of every HCC to improve performance and customer care services. HCCs may experience growth and positive feedback from patients by employing a firm and positive HCM. HCMs must provide emotional support, schedule meetings, and advise their employees (Engle et al., 2017). The multiple roles of HCMs are not limited and can provide strategies for UCMs who oversee employees in UCCs. Expectation strategies can help UCMs provide effective leadership to improve customer care services and extend services to the community.

\section{Concepts of UCCs}

UCCs changed the modern-day treatment of patients. In the early 2000 s, walk-in UCCs phenomenon began as an alternative to expensive and time-consuming options such as hospital emergency rooms and physician office visits (Hermanson, Berkshire, Leaming, \& Piland, 2013). Most were identifiable by four characteristics, including location within a big box retail store or pharmacy, a limited menu of services that did not require imaging or laboratory services, nurse practitioners, and affordable pricing structures (Wright, 2017). Visibility and accessibility attract more customers to the business.

Individuals were seeking to bring change to the $\mathrm{HC}$ model own and operate UCCs. Minority small business owners also capitalized on this market (Hermanson et al., 2013). By identifying costs associated with local health care, UCMs can capitalize on competitive advantages to make UCCs more successful. Patient visits, leadership commitment, marketing, staffing, and location were the most cited factors as the key determinants of repeat sales (Beausejour et al., 2015). More opportunities existed for patients and individuals seeking small business ownership. Beausejour et al. (2015) stated within the regular source of care, communities could see relational, informational, and management continuity with the inclusion of UCCs in their community.

Patient Protection Affordable Care Act. In March 2010, Congress passed a law expanding the guidelines for Americans to accept health care coverage, and regulate policies offered by insurance companies (Stake, 2010). The PPACA of 2010, better known as Obamacare, awarded incentives to HC leaders for improving performance and patient services (Stake, 2010). Many Americans not insured were able to enroll either individually, or their entire family in Obamacare. Prior to Obamacare, many Americans were without HC because of excessive premium costs (Skinner, 2014). The Center for Medicare and Medicaid Services (CMS, 2014) created several programs to increase patient services in the HC industry. Value-based programs (VBP) reward health care providers with incentives based on the quality of service performed (Dupree, Neimeyer, \& Mchugh, 2014). According to CMS (2015), the three major components of VBP include: 1) better patient care; 2) improve the health in the population, and 3) affordable cost. More than 100 million Americans enroll in some type of Medicare or Medicaid program operated by the CMS (CMS, 2015). Consequently, the 
CMS takes full control over ensuring patient satisfaction by demanding HC organizations provide quality customer care services to their patients.

Consumer assessment and patient satisfaction. Systematic accountability may improve the quality of customer care services and patient satisfaction. The hospital consumer assessment of health care providers and Systems (HCAHPS) is an assessment model used to measure and evaluate health care providers on the patient (CMS, 2014). According to Iannuzzi et al. (2015), the HCAHPS has seven components that measure patient satisfaction 1) communication, 2) response time, 3) pain management, 4) new medicine, 5) facility cleaning 6) patient discharge, and 7) post-op knowledge. After the patient leaves the HC facility, within 48 hours, the HCAHPS will send out a random survey. According to the HCAHPS, the primary section of the survey consists of 21 questions asking the patient to evaluate their visitation. The surveys from the HCAHPS provide data beneficial to both the patient and the manager to improve satisfaction.

Customer care. Organizations have an obligation to ensure high-quality customer care to individuals patronizing their establishment. Mohebifar, Hasani, Barikani, and Rafiei (2016) suggested that properly equipped, clean, and customer friendly facilities attract customers. Competition exists in HC facilities, and managers understand patients are demanding satisfactory customer care services (Pflueger, 2016). According to Pflueger (2016), in 1985, the two efforts placed on health care included: 1) measure of health care and 2) quality of customer care. The efforts determined the quality of customer care services and government price control. During governmental price control, judging and checking customer care services can be difficult. Pflueger (2016) argued that nurses and acting physicians measured customer care services, leaving the customer without any input on services given. Therefore, UCMs can learn from this by allowing customer input to improve customer care services and patient satisfaction.

Strategies to increase patient satisfaction. UCMs should take strategic steps to guarantee all their patients are satisfied with their customer care services. Saadat, Panah, and Noroozi (2017) indicated that $72 \%$ of patients are satisfied with the quality of customer care services they receive from HC professionals. Therefore, $28 \%$ of patients feel they received dissatisfactory customer care services. Key factors such as positive managerial strategies and quality customer care can increase patient satisfaction. Both HC professionals and patients have responsibilities in ensuring patient satisfaction. Schaufeli (2015) suggested that leaders of $\mathrm{HC}$ facilities can engage employees by paying competitive wages and offering rewards to their employees. Rewarding employees for their service can help UCMs increase employee engagement. Engaged employees can offer a positive environment that welcomes new or repeat patients in their UCC. Schiff et al. (2016) argued that HC professionals waste millions of dollars each year on wrongful and unwanted examines.

\section{HC Sustainability}


Few organizations invest in practices targeting sustainability. Family ties to future generations within transgenerational succession could change as the adoption of sustainable practices change (Delmas \& Gergaud, 2014). Transgenerational framing strategies may improve patient satisfaction and increase sustainability through concept innovation. Fleiszer, Semenic, Ritchie, Richer, and Jean-Louis (2015) noted sustainability benefits from the endurance of innovation-related benefits, as well as the continued development of innovation over time. Sustainability educators (SE) proposed the definition should integrate all three characteristics of the business model (Wyness, Jones, \& Klapper, 2015). Sustainability is a descriptive analysis research tool used to measure and balance sustainable strategies against competing interests (Starik \& Kanashiro, 2013). When managers of UCCs use guidelines associated with sustainability, they increase their chance of having a competitive advantage and repeat business (Srivastava \& Rai, 2014). Additional sustainability benefits include increased repeat business and new business development because customers tend to conduct business with real branded companies. Wyness et al. posited that the inclusion of sustainability into entrepreneurial activity remains a niche topic within the entrepreneurship literature. Many sustainability theory research articles were about environmental sustainability and business sustainability. Steinmeier (2016) noted the situation was not clear whether small businesses possess the required time to follow the type of sustainability processes and guides available. Sustainability theory scholars encourage appreciation of the interconnectedness of the world's systems and processes, therefore lacking strategies to improve customer care services and patient satisfaction.

\section{Relationship of the Study to Previous Research and Findings}

Researchers found a distinguished difference between the elements of loyalty and customer satisfaction. Satisfaction and loyalty elements align with the perception generated by the customer, and each element may increase organizational leadership (Babin et al., 2015). Similar relationships between customer attitudes and behaviors increase customer satisfaction and demand for quality (Sahin Dölarslan, 2014). Satisfaction affects the consumer's willingness to pay for the service and is an impact on a company's financial performance; however, the relevancy to improve customer care services and patient satisfaction remains absent in UCCs.

Although statistical differences exist in customer loyalty, researchers identified demographic factors as the major concept of the model. Demographic changes, for example, age, marital status, children in the household, and changes in economic situations, altered customers' evaluations of a product or service (Lariviere, Keiningham, Cooil, Aksoy, \& Malthouse, 2014). In addition, younger customers are more loyal to branding and staying faithful to a company over their lifetime more than adults over 30 years of age. Klopotan, Vrhovec-Zohar, and Mahic (2016) proposed a four-stage customer loyalty model that encompasses a customer's belief, affect intentions, brand loyalty, and action. Business 
managers who use the four-stage loyalty model may experience negative feedback from older customers; however, they can gain loyalty from younger customers in the demographic region. Despite many similarities of CLT, the model lacks customer care strategies to improve patient satisfaction.

\section{Research Method and Design}

\section{Research Method}

Three research methods are available to researchers to conduct a research study. Researchers can select qualitative, quantitative, or mixed methods (Yin, 2017). The qualitative method is exploratory research, useful for interviews, and is effective in human data collection (Sandelowski, 2015). The qualitative research method is a combination of data codes, interviewing, and textual understanding from participants (Berger, 2015). Business leaders share their experiences through the qualitative method of research (Daghan \& Akkoyunlu, 2014). Theories develop when researchers observe and interpret reality in qualitative studies (Merriam \& Tisdell, 2015; Newman \& Benz, 2006; Strauss \& Corbin, 2015). Testing human subjects in quantitative and mixed-method research designs justify using qualitative methods (Yin, 2017). After reading and analyzing other research designs for the study, I decided to use a qualitative research method for this study. The qualitative research study method was appropriate for the research question, which requires a thorough exploration of strategies managers used to improve customer care services and patient satisfaction.

\section{Research Design}

I used an embedded single case study design for this qualitative research study. To understand the complexity of a social phenomenon, researchers perform case studies (Merriam \& Tisdell, 2015; Stake, 2010; Yin, 2017). Researchers consider a case study design when the focus of the study is answering how and why questions, and when the study involves human behavior (Yin, 2017). In addition, a case study is necessary when the researcher plans to cover contextual conditions that are relevant to the phenomenon and context (Koopman, 2015). The focus of this study was to explore a complex social phenomenon involving UCMs and customer care strategies to improve patient satisfaction.

Reaching data saturation is imperative in qualitative research studies. Data saturation achieves when sufficient information is available to duplicate the study (Fusch \& Ness, 2015). According to Marshall, Cardon, Poddar, and Fontenot (2013), data saturation occurs when no new information emerges from the interview process. Additionally, researchers achieve data saturation when no new themes and the information collected become redundant (Burda, van den Akker, van der Horst, Lemmens, \& Knottnerus, 2016). Therefore, I repeated the process of going over additional information with the participants until the data collection provided no new themes, insights, perspectives, or new information. I collected enough information to replicate the study.

\section{Population and Sampling}


The population for this study included three UCMs in Alabama who used strategies to improve customer care services and patient satisfaction. I used purposeful sampling to select the participants for the study. Purposeful sampling is widely used in qualitative research for the identification and selection of information-rich cases related to the phenomenon of interest (Palinkas et al., 2013). According to Apostolopoulos and Liargovas (2016), researchers should select participants with relative knowledge of the research subject. Leaders of organizations are great for purposeful sampling (Nicol, Mohanna, \& Cowpe, 2014). Some situations require managers or other key individuals to be the primary source of data collection (Yin, 2017). Purposeful sampling requires access to key participants in the field who can help in identifying information-rich cases (Suri, 2011). I was interested in participants sharing information to support the research topic.

The population for this qualitative embedded single case study consisted of three UCMs who used strategies to improve customer care services and patient satisfaction. The three participants worked at different UCCs; however, each UCC fell under the same organizational franchise. The three UCMs provided three separate collections of data. The criteria for selecting the participants for the study predicates on their knowledge of customer care services and patient satisfaction. In a qualitative study, the researcher defines the population sample (Bryman \& Bell, 2015). Additionally, a sample size of three to 20 individuals is appropriate for qualitative research (Stivala, Koskinen, Rolls, Wang, \& Robins, 2016). Once a participant identifies individuals in the snowball, the researcher may request respondents to refer others in the same demographic that may be interested in the research study (Morse, 2015). A sample from the larger population is ideal; however, 15 UCCs are in this scope; therefore, I chose a snowball sample size of three.

\section{Data Collection Instruments}

I was the primary data collection instrument in this qualitative research study. In qualitative studies, the primary data collection instrument is the researcher (Yin, 2017). Additionally, Marshall and Rossman (2016) stated the researcher is the primary instrument in data collection. I conducted semistructured interviews to collect data from UCMs implementing customer care strategies to improve patient satisfaction.

The method for data collection included eight opened ended face-to-face semistructured interview questions with three UCMs. The face-to-face interview method emulates the needs of the researcher by garnering as much information as possible (Comi, Bischof, \& Eppler, 2014). The researcher establishes clarity through the semistructured interviewing technique with open-ended questioning (Harvey, 2015; Marshall \& Rossman, 2016; Strauss \& Corbin, 2015). I used a digital voice recorder to document the interview for accuracy. The informed consent form for a study is a set of two rules intended to respect a participant's autonomy; and protect members from harm (Tam et al., 2015). I sent each par- 
ticipant a copy of the consent form, as well as all my personal contact information. Upon completion of the recording, I then transferred the collected data to my laptop, and then I used audio transcription (Voicea) software to transcribe the data. I searched for key meanings; organized the data to look for codes and common phrases collected from the interviews.

\section{Data Collection Technique}

I collected data using semistructured face-to-face interviews with open-ended questioning. Semistructured interviews enable the researcher to maintain research consistency and collect rich data in the interviews (Strauss \& Corbin, 2015). Some participants may not be overly talkative during the interview and especially in unstructured interviews (Rowley, 2012). I performed semistructured interviews with open-ended questioning that enabled participants to talk about the research topic openly. I had an interview protocol to ensure the academic soundness of research in academic inquiry. Sarma (2015) stated validation of research achieves through qualitative scientific inquiry and interview protocol. Additionally, an interview protocol is a substantive frame used to gather information for qualitative inquiry (Sarma, 2015). Some business owners create company websites providing academic information for the general public. Therefore, my fourth source of data collection came from internet survey forms.

I used archival company internet survey forms from UCCs websites that gave patients an opportunity to rate their physician and visit. Archival company data is a supplementary source of data collection researchers use (Gibbons, 2015). According to Hopper and Uriyo (2015), the best place to find comments on physicians and data, relating to patient satisfaction is on the World Wide Web. Additionally, several company websites let patients share their customer care experiences. For example, anyone concerned with selecting the best physician with good ratings can visit www.ratemds.com. In addition, they can also find out which physician or facility offers the least desirable customer care services.

\section{Data Organization Technique}

Organizing and storing multiple sources of data is important in qualitative research. Carter, Bryant-Lukosius, DiCenso, Blythe, and Neville (2014) suggested that data organization is imperative when a researcher collects multiple sources of data. I developed a labeling system to track data and emerging themes collected from the participants. I used a labeling system separating the individuals using the following codes: 1) interviewee one (P1), 2) interviewee two (P2), and 3) interviewee three (P3). I then gathered similar themes from the data and highlighted them using the same color codes. Coding is for researches to decipher underlying information while keeping the names of participants confidential (Qayyum, 2015). Coding and storing data ensured confidentiality. In addition, coding participant's information protects their identity (Ranney et al., 2015). After the in-depth interviews and notes were on the computer, I formatted the data for analysis in NVivo. I used NVivo software to organize the collected data and ensure reliability. Woods, Paulus, Atkins, and Macklin (2016) stated that NVivo software is best for coding, comparison, and checking for re- 
liable consistency.

\section{Data Analysis}

I used a logical, sequential process to analyze the data collected from the participants. The qualitative data organizing software assisted with the analysis and organization of the participant's information and archival company survey data. Software designed for qualitative data analysis and data organization is NVivo (Castleberry, 2014). After I collected the data from the three UCMs and archival company internet survey forms, I organized the data to look for codes and common phrases collected from the sources. Next, I transcribed and interpreted the information and then dismissed irrelevant material. I then checked with the participants to ensure the interpreted responses were accurate and free of errors. Member checking is the process of sharing interpreted data with participants to ensure the accuracy of the information collected (Marshall \& Rossman, 2016). Following the interview protocol and member checking process, I then analyzed my sources of collected data.

I used NVivo software to organize the data collected from the UCMs and archival company internet survey forms. NVivo software organizes the data in HC research and multiple organizations. According to Woods et al. (2016), research on NVivo, proved HC organizations use the software more than any other organization to organize data. NVivo software is a great source for coding and creating relational pairing for grouping and sourcing (Kotula, Ho, Dey, \& Lee, 2015). According to Houghton, Casey, Shaw, and Murphy (2013), NVivo is a great software to use in a case study analysis. Woods et al. argued that NVivo software is best for coding, comparison, and checking for reliable consistency. I uploaded the participant's interviews and archival company internet survey forms into NVivo. I saved the information as P1, P2, P3, and company survey results. I also grouped any related information into nodes before coding. After reviewing the generated data, I extracted all relevant material and presented the findings in the results section.

I analyzed the data, searching for relative information. I searched and read all relative data and looked for comparisons. The data from the study received analysis and coding in the form of labels. Koopman (2015) indicated that researchers examine codes and themes through the process of thematic analysis. I used Yin's thematic analysis process to analyze the data. Yin (2017) stated thematic analysis is good for the following: 1) interpreting data, 2) deductive and inductive methods, 3) analyzing two different processes, and 4) coding and pattern recognition. Using thematic analysis, I emerged the themes and interpreted the data. I looked for corroborating themes relating to recently published studies.

\section{Reliability and Validity}

Researchers use reliability and validity to test the measurement of research. Researchers increase the integrity of data collected through reliability and validity (Barry, Chaney, Piazza-Gardner, \& Chavarria, 2014). According to Noble and 
Smith (2015), validity and reliability practices support research standards by addressing the research instrument, and the overall research measurement consistency. However, many researcher overlook the standards. The standards need verification using qualitative methods, for example, member checking, and triangulation (Marshall \& Rossman, 2016). Member checking is interpreting a participant's data and checking for any misinterpretations (Strauss \& Corbin, 2015). Methodological triangulation provides the researcher using multiple data collection techniques with a more comprehensive picture (Marshall \& Rossman, 2016). I provided detailed information on the research design, research methods, participants, data collection procedures, data analysis, and data organization to enhance the reliability and validity of the study.

\section{Reliability}

Duplication can occur on reliable and dependable information. The consistency of data collection instruments increases dependability in qualitative studies (Munn, Porritt, Lockwood, Aromataris, \& Pearson, 2014). Research is dependable when proper documentation and member checking are performed (Marshall \& Rossman, 2016). I ensured dependability by using proper data collection protocols in the interview process. A constant data collection protocol allows future researchers to replicate the study and find comparable outcomes (Jacob \& Furgerson, 2012). I also performed member checking with each participant. Member checking is sharing interpreted interview data with the participant for accuracy and validation of their responses (Strauss \& Corbin, 2015). Additionally, I audio recorded the participant interviews and then transcribed the recorded audio. I ensured dependability and reliability by summarizing the interview data and then having the participant review a summary of the transcripts through email to look for any discrepancies or errors for validation. In addition, I synthesized the data results by utilizing NVivo, a qualitative data organizing software. Through data transcription, member checking, and the use of NVivo data software, I enhanced the dependability of my study results.

\section{Validity}

Credibility, transferability, and confirmability will serve as the basic construct to validate the data. The specific criteria that validate a study for qualitative research include 1) dependability, 2) creditability, 3) confirmability, and 4) transferability (Houghton et al., 2013). Researchers maintain credibility by verifying differences between the information collected and the interpretation of the participants' responses (Munn et al., 2014). The primary researcher (instrument) is responsible for collecting rich and accurate data to ensure credibility. I was the primary data collection instrument in this qualitative study; therefore, I collected data from three sources to ensure credibility.

\section{Findings}

This section contains user information pertaining to the emerging themes from the interviews, participant identification codes, and interview protocols. What 
customer care strategies do UCMs use to improve patient satisfaction? Dick and Basu's CLT was the conceptual framework of this study. To ensure the privacy of my three participants and their data, I assigned each participant a personal identifying code (P1, P2, and P3). In addition, the identifying codes for data collected from the 10 internet survey results from the patients received coding as PS1, PS2, PS3, PS4, PS5, PS6, PS7, PS8, PS9, and PS10.

I used data from semistructured interviews and company internet survey results for this study. The three participants responded to interview questions sharing their knowledge and strategies on how they provide customer care services. In addition, I analyzed 10 company internet survey results from patients who visited the UCC. There were four themes derived from the analysis: patient-focused care, follow-up callbacks, social media outreach, and employee engagement.

\section{Theme 1: Patient-Focused Care}

HC leaders rely on quality measurement programs to ensure patient-focused care occurs. According to the data analysis, patients are satisfied with customer satisfaction, and UCMs place emphasis on customer care services. Each participant shared placing the needs of their patients first and shared the motto that the customer is always right. Consequently, managers and HC professionals improved customer care services by working to build programs to strengthen relations with their customers. P1 indicated that the primary focus of the UCC is for the patient to feel free to express their concerns to the administration. In addition, P1 stated that their organization had a drobox program. The drobox is where a patient can leave a note or message in the front office to share their experience, suggestions, or any concerns they may have. In addition, P1 stated:

Every person that comes into the clinic leaves their email. They [patients] receive a review survey sent to them through email from Google or Facebook (FB). Most of the time, it is through Google review. The patient can go in on Google to leave comments, either positive or negative.

P2 stated, "UCCs are more beneficial to the customer because of the wait time". In addition, $\mathrm{P} 2$ stated:

We believe in greeting every patient that comes to our clinic. Every patient that comes to the clinic will be acknowledged, and we let them know we saw them come in, and that they have been seen and recognized. We introduce ourselves to the patient and reach out to them with a few questions such as 1) whom you would like to see, 2) would you like something to drink, and 3) would you care for a treat bag. We also let them know the approximate wait time and our procedures. We try to make their wait time and visit as short as possible, but ensuring them that we pay attention to their needs and medical care.

Each participant indicated that they were committed to keeping their patients 
satisfied, as well as remaining aware of the sustainability of their organization. P3 stated:

You have to be mindful that we are trying to do the best for the patient, so we are trying to make them happy, but at the same time, we are a medical facility, so the patient doesn't always get the treatment that they want. Sometimes they come in and say "I want this, and I want that", but we must do what's in the best interest of the patient, and at the same time try to keep the patient happy, so it's kind of a hard thing to try to keep your patient satisfied, and do correct medicine.

In addition, P3 stated, "There is a fine line between trying to meet the patients' wants and offering them the proper medical care they need". In addition, P3 also stated, "each patient should be treated with proper care and given the best quality of services that can be offered", and similarly, P2 stated, "after each visit to the clinic, there is follow up callback process to check on the patient". As indicated in Figure 1, patients who visit this UCC are satisfied with the quality of patient-focused care they receive from their nurses and physicians. Results from the survey showed that PS2, PS4, PS5, PS7, and PS9 each rated patient-focused care 10 out of 10. Data results from PS1 and PS6 showed that their patient-focused care rating is 0.5 lower than the other patients but still rated high at 9.5. Findings from the surveys indicate that patients rated their bedside manner with the physician at 9.7, and the nurse bedside manner at 9.2. The overall rating for patient-focused care is 9.8 for the physicians and 9.1 for the nurses. In triangulating the data from interviews and survey results, the data collected from the survey results supported data collected from the interviews on patient-focused care.

\section{Theme 2: Follow up Callbacks}

The second theme that emerged from the participants was a patient callback. Follow up procedures are important to patients in the HC industry. According to my analysis, the followup callback system is innovative, and it allows physicians and nurses to call patients after their visit, and effectively communicate

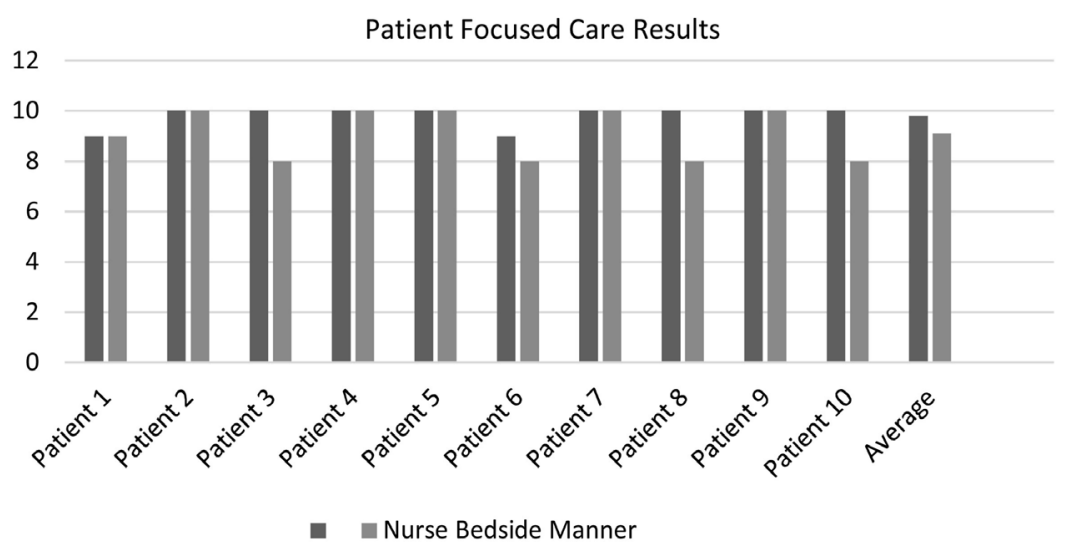

Figure 1. Nurse and physician patient-focused care results from internet survey forms. 
them on a personal level. Each participant believed they should let the patient know they care about their wellbeing by way of a phone call. P3 stated that the companies' followup calls are made for various reasons ranging from lab work to check up on patients. P1 stated:

If you were a patient, we attempt to call the number that you've left as a follow-up, uh, within one to three days. Often times, we try the next day or the second day, and just to make sure the patient is fine, having any issues or anything like that. We attempt to callback on everyone just to see how everything's going. It's kind of the big three things that we use.

Similarly, P2 stated:

One of the biggest things we do is callbacks. Every single patient that comes in here, every single one is called back within anywhere from two to four days after their initial visit. We call them, we check on their visit, we see how they're feeling. If they're [patient] feeling better, if there's anything they need to change, you know, is the medicine not working, or they not getting better and feeling worse. We also want to know how their visit was. We like to get it straight from them, and there's no better person to ask than the patient.

In addition, $\mathrm{P} 3$ stated,

I think one of the main things that we've tried to do to improve patient satisfaction is we always do a callback after their visit. We check on them to see how they're doing it, to see if the treatment that we did is improving their symptoms. If the patient says no, then the front desk transfers it to a nurse, and from there, we can kind of direct the patient to continue their antibiotics or if they're not feeling better, come back in.

Various strategies in the HC field may ensure patient satisfaction. Each participant indicated that they were not part of a large franchise and needed to have a personal relationship with their patients. Therefore, they use inexpensive strategies to reach out to their patients. Follow up calls and social media strategies are ways that the organization can reach out to their patients at a relatively low cost.

The survey results did not address information on physician or nurse follow up calls. However, results from the company internet survey forms showed that patients were able to follow up with the physician or nurse to get results and do follow up reviews. In triangulating the data from the interviews and survey results, the findings from the survey results supported the interview data on the follow-up callback system and extended knowledge on research to improve customer care services in UCCs.

\section{Theme 3: Social Media Outreach}

The third theme that emerged from my data analysis was social media outreach to increase customer care services and patient satisfaction. Social media 
has become a strategic instrument for businesses reaching out to current and potential customers. My analysis of the data indicated that positive feedback and comments on social media promote engagement between UCMs and patients. Each participant agreed that using FB and their company website were great tools for ensuring proper communication with their patients. All participants mentioned their patients appreciate the open communication and rewards offered on social media. P1 stated, "Data ratings posted on social websites capture the experiences of a systematic, controlled organization". P2 stated, "We use FB to help our clinic gain credibility in our community". In addition, P2 stated,

We like to use social media. You would be surprised how fast you can put the word out, and that makes a difference. We've actually tweeted stuff before. When we put stuff on FB, within minutes, people are coming in and mentioning things about it. So I mean it's instantaneous.

Similarly, P3 stated,

We do a lot of social media with Google reviews, and we have FB marketing where patients can leave their reviews, and if anytime a patient does have a negative view or have a bad experience, we do try to contact that patient and see what went wrong, what we did wrong, and what we could do better in the future to improve. We need to understand how we can satisfy our clients and know how to handle situations. So we always try to go back and see when patients leave comments, whether they be positive or negative, I mean a lot of times if we get a positive comment we try to share that with the staff because I feel like that also boosts morale for people to treat people better. So I think by having the comment boxes and doing the whole review system, I think that kind of help to increase patient satisfaction.

All comments from patients were not complimentary reviews. P3 stated, "They feel that it is important to receive all types of feedback whether it be positive or negative". Evidence collected from participants found that social media increases and strengthens relationships between businesses and the customer. Social media interaction within an organization can cultivate positive employee engagement.

The company internet survey forms did not address any organizational information on social media. Therefore, I cannot confirm nor disconfirm that social media outreach improved customer care services and patient satisfaction at the UCC. However, the patients were able to offer reviews from the survey and make comments on the company's FB page. Data collected from the participants concerning feedback and comments on their FB page confirm that strategies to increase feedback and comments on their social media outreach improved customer care strategies at the UCC. By triangulating the data from the interviews and internet survey results, I was able to find evidence that the patient feedback and comments on the UCCs FB page extended knowledge on data collected from the interviews. 


\section{Theme 4: Employee Engagement}

The fourth theme that emerged from the data collected was employee engagement. Employee engagement is important in creating a culture conducive to satisfaction. According to my data analysis, employee engagement strengthens relations with staff members, and creates a positive environment for customer care services and patient satisfaction. All three participants agreed that informing employees on patient feedback is important to the growth of their organization. P2 stated, "We asked the staff a lot of times; what do you think we should do differently if things are slow"? P2 stated,

A lot has to do with the staff, and we try to hire good staff. All staff should be nice and friendly to people. You should always have a nice person that greets them (patient) and talks to them. You want them to ask the patient, how are you doing? When they see the nurses, they do the same thing. When they leave, we tell them, hope you feel better when they walk out the door. You will be surprised at how a little bit goes a long way. I always say, kill them with kindness.

Similarly, P3 stated,

We tried to teach the employees to be respectful to the patient and to kind of treat the patients as they would their family members, and how they would want their family members to be taken care of. I feel like it's all in the training of your staff. It's not really cost that you have to put into it. It's more of an in house thing where you make sure that you're hiring the right people and people that are actually genuinely wanting to care for other people. I feel like that is more valuable than spending money on, I guess outside resources. I feel like we just try to hire the right staff and the right people to deal with the customers. I feel like that is, you know, really an invaluable resource and you don't really have to spend a lot of money on it.

Creating an environment that is conducive to positive work culture is important to employee engagement. P3 stated, "Employees work better in a friendly work environment". Engaged employees are more likely to be dedicated, trustworthy, and friendly to their customers, which can strengthen organizational outcomes and professional practices. As indicated in Figure 2, the findings confirm that the patients felt satisfied with employee engagement and gave the UCC a 9.5 score rating. The findings show that eight of the patients that visited this UCC rated the registration process a 10 out of 10 . In addition, the findings show that PS1-PS10 rated the friendliness of staff engagement at 9.2. Survey results indicate that PS3 and PS5 both had identical score ratings of 10.0 and 8.0 on employee engagement from their visit to the UCC. Moreover, additional evidence from the surveys shows that PS6, PS7, and PS9, each rated the UCC a 10 on satisfactory employee engagement, ranking them the highest among the patients. After reviewing the data from the interviews and internet survey results 


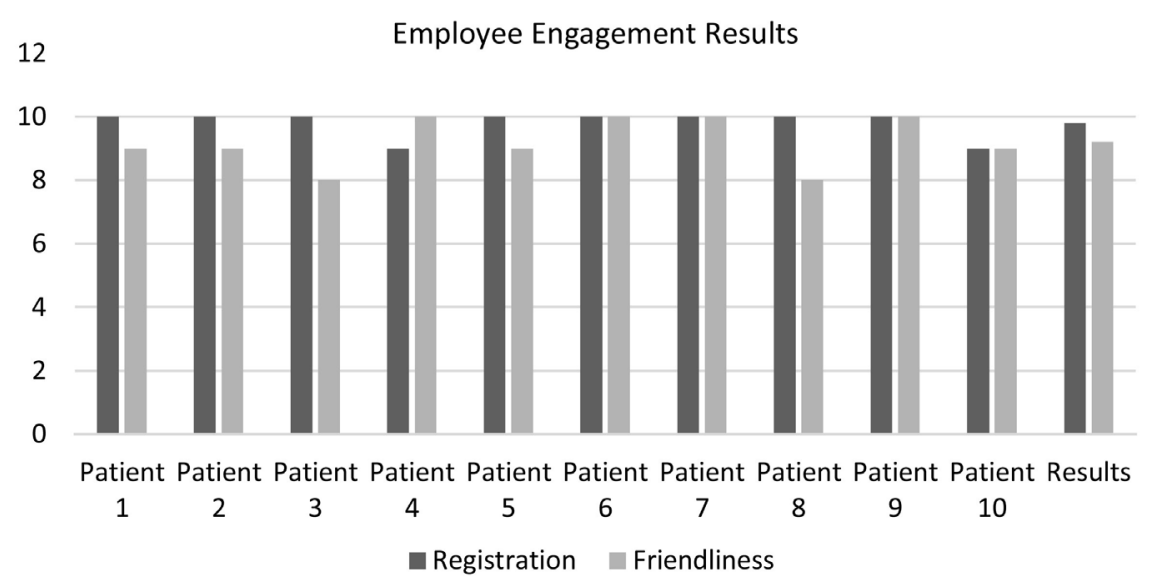

Figure 2. Employee engagement results from internet survey forms.

on employee engagement, I was able to confirm that employee engagement improved customer care services and patient satisfaction. Data from the interviews received support by data collected from internet survey results on employee engagement.

\section{Company Survey Forms Review}

Patient-centered company internet surveys are welcomed at the participating UCC. According to Gibbons (2015), archival company data is a supplementary source of data collection researchers use. In addition, Hopper and Uriyo (2015) posited that the best place to find comments on physicians and data relating to patient satisfaction is on the World Wide Web. After reviewing 10 anonymous patient internet survey forms, results show that the facility received 9.4 out of 10 score ratings with their patients on satisfaction and services offered (see Figure 3).

The 10 company internet survey forms served as another source of data collection. Each form had a rating score of $1-10$, with 1 being the lowest and 10 being the highest. There were seven key components on the survey forms which included: 1), registration process, 2) friendly of front desk staff, 3) physician bedside manner, 4) nurse bedside manner, 5) clarity of communication, and 6) overall timeliness of visit. The highest rating of the data was the cleanliness of the clinic and the physician's bedside manner with a score of 9.8 out of 10 . Patients that visited this UCC facility felt that the facility was clean, and the physicians tended to them with care. The median of the group was overall timeless of visits, clarity of communication, friendliness of front desk staff, and registration process, averaging a score of 8.9. Evidence from the surveys showed that the overall wait time was sufficient, their procedure was communicated with them accurately, and the staff's demeanor and registration process was adequate. The lowest of the scores was nurses' bedside manner scoring an 8.2 out of 10, which is still extremely high. Nurses have a daunting task to draw blood, collect culture samples, and still must convince the patient on customer care and patient satisfaction. The overall score from all seven groups was 9.4 out of 10 . The scores 


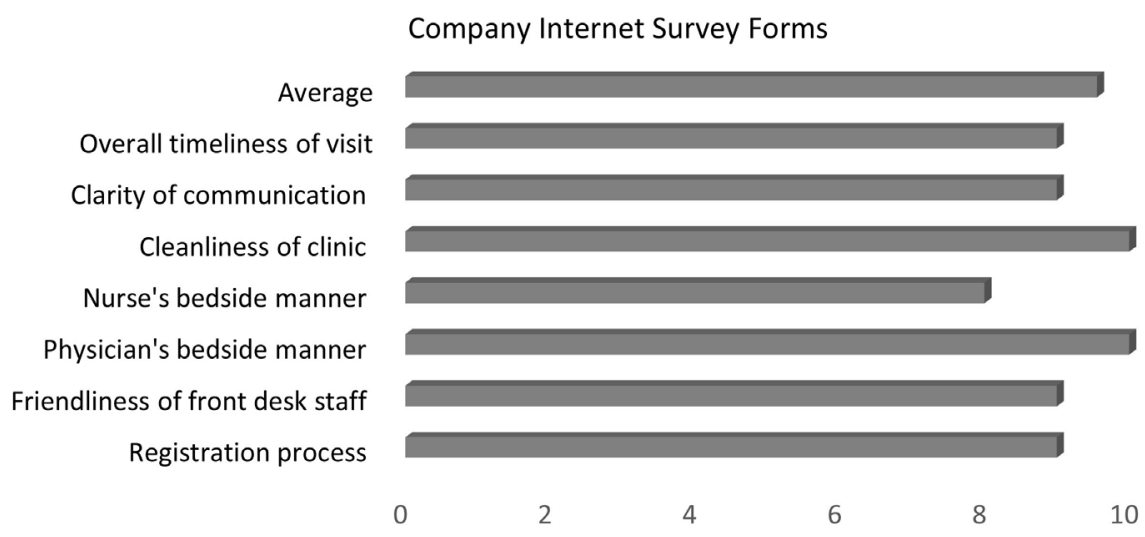

Figure 3. Overall, patient survey feedback from UCC.

from the study indicate that this facility is doing an outstanding job ensuring their staff members, doctors, and nurses practice a high quality of customer care services.

\section{Discussion}

Findings in the study supported the efforts of the UCMs' strategies on improving customer care services and patient satisfaction. The customer care strategies they shared are imperative to effective business practices. UCCs are new, which presented a challenge comparing and disputing the findings in the study due to the lack of research done on this topic. However, in comparison to previous research on customer care services and customer loyalty, there was limited information on reward programs that offer discounts or incentives to the consumer. The participants in this study noted that to have an effective business practice, the organization must rely on positive word of mouth from the customer. They felt that it is more sustainable for the organization to do a lot of "personal legwork" than rely on spending thousands of dollars on marketing. P1 stated, "We're not going to spend $\$ 50,000$ on something that doesn't work, we like to keep it simple". In addition, the participants stated they are a "Mom and Pops Clinic", which rely on a lot of community engagement to attract new customers. The results of this study indicated there were effective business strategies on customer care services that can apply to improve patient satisfaction.

\section{Implications for Social Change}

The purpose of this qualitative embedded single case study was to explore the strategies UCMs used to improve customer care services and patient satisfaction. Customer care services and patient satisfaction in health care are major concerns for business leaders and community members. Adequate customer care services have a direct impact on customer loyalty and repeat business from community members. Community members refer to friends and family members to organizations that have a large and diverse group of satisfied customers (Costanza \& Finkelstein, 2015). The study results may contribute to positive social change by helping UCMs provide a higher quality of customer care services, which could 
benefit local communities by decreasing illnesses and improving patient satisfaction in HCCs.

\section{Recommendations for Action}

The results of this study could influence existing and future businesses in HC. My recommendations are for business leaders, HC organizations, patients, and community members. My specific recommendations for action on improving customer care services and patient satisfaction consists of 1) focus on the patient, 2) implement programs to receive feedback, and 3) create a friendly environment. Participants in the study emphasized the importance of focusing on the patient and providing proper medicine.

Organizational leaders in $\mathrm{HC}$ can better understand what their patients are seeking through patient-focused care. Leaders in HC are aware that patients realize the importance of the organization paying attention to their needs. Leaders must focus on making each patient feel they are a priority and provide quality medical care. Priority is important in satisfying a patient and practicing good customer care services. Providing high-quality services can support the organization even if the patient feels as if their wants and needs neglected. Therefore, organizations should implement programs in case an acute situation may arise.

I recommend HC organizations have programs to listen to feedback from their patients. The implementation of the three programs is a drobox, callback system, and internet survey program. The drobox program is a way that patients can leave anonymous comments at the facility pertaining to their experience or make a recommendation. The second program is a callback system to check on the patient after their visit or remind them of an appointment. The third and final program is an internet survey review form where patients can anonymously comment on their experience with a particular physician, nurse, or staff member. Implementation can occur of these three programs to increase customer care services.

\section{Recommendations for Further Research}

The research will always be at the core existence of science to improve, contradict, or confirm previous research. The findings from my study derived from three interviews and 10 company internet survey results. A small amount of my study came from limited information from previous research studies on UCCs. Several limitations existed in gathering information, resources, and data for this study. Moreover, I used a qualitative, embedded single case study to collect data. In addition, I only collected data from Alabama, and only used one organization, which was a limitation.

Therefore, I recommend for future research to expand the geographical region beyond the scope of Alabama. Alabama is a small and rural state lacking many resources to conduct a study. Larger and more diverse states have more HC facilities, which means they can collect more information. Neighboring states such as Florida and Georgia have both UCCs and Walk-In Retail Clinics, which can be another source of data collection for future research. 
Another recommendation for future research is to expand the number of participants, research multiple organizations, and use the patients as participants. More participants will offer a larger amount of data for collection. In addition, there may be more strategies and suggestions on improving customer care services and patient satisfaction. My final recommendation for future research is to expand the research design by conducting a multiple case study.

\section{Conclusion}

Patient dissatisfaction is a major topic for managers, resulting in a need for better customer care services in the HC industry. With increasing patient satisfaction expectations, the demand for better community-based health care facilities has become extremely important. The findings from the study indicated that UCMs used the following strategies to improve patient satisfaction: 1) patient-focused care, 2) follow up callbacks, 3) social media outreach, and 4) employee engagement. UCMs can take strategies from this study to help their UCC remain sustainable, retain new loyal customers, and enhance a customer care model to improve patient satisfaction in their community.

\section{Conflicts of Interest}

The author declares no conflicts of interest regarding the publication of this paper.

\section{References}

Al-Abri, R., \& Al-Balushi, A. (2014). Patient Satisfaction Survey as a Tool towards Quality Improvement. Oman Medical Journal, 29, 3-7. https://doi.org/10.5001/omj.2014.02

Apostolopoulos, N., \& Liargovas, P. (2016). Regional Parameters and Solar Energy Enterprises: Purposive Sampling and Group AHP Approach. International Journal of Energy Sector Management, 10, 19-37. https://doi.org/10.1108/IJESM-11-2014-0009

Askariazad, M. H., \& Babakhani, N. (2015). An Application of European Customer Satisfaction Index (ECSI) in Business to Business (B2B) Context. The Journal of Business \& Industrial Marketing, 30, 17-31. https://doi.org/10.1108/JBIM-07-2011-0093

Babin, B. J., Boles, J. S., \& Griffin, M. (2015). The Moderating Role of Service Environment on the Customer Share Customer Commitment Relationship. In New Meanings for Marketing in a New Millennium (pp. 266-271). Cham, Switzerland: Springer. https://doi.org/10.1007/978-3-319-11927-4_90

Barry, A. E., Chaney, B., Piazza-Gardner, A. K., \& Chavarria, E. A. (2014). Validity and Reliability Reporting Practices in the Field of Health Education and Behavior: A Review of Seven Journals. Health Education \& Behavior, 41, 12-18. https://doi.org/10.1177/1090198113483139

Beausejour, M., Goulet, L., Debbie, E. F., Roxane-Borges, D. S., Pineault, R., Rossignol, M., \& Labelle, H. (2015). Pathways of Healthcare Utilisation in Patients with Suspected Adolescent Idiopathic Scoliosis: A Cross-Sectional Study. BMC Health Services Research, 15, 2-12. https://doi.org/10.1186/s12913-015-1152-1

Berger, A. A. (2015). Media and Communication Research Methods: An Introduction to Qualitative and Quantitative Approaches. Thousand Oaks, CA: Sage. 
Brutus, S., Aguinis, H., \& Wassmer, U. (2012). Self-Reported Limitations and Future Directions in Scholarly Reports Analysis and Recommendations. Journal of Management, 39, 48-75. https://doi.org/10.1177/0149206312455245

Bryman, A., \& Bell, E. (2015). Business Research Methods. New York: Oxford University Press.

Burda, M. H. F., van den Akker, M., van der Horst, F., Lemmens, P., \& Knottnerus, J. A. (2016). Collecting and Validating Experiential Expertise Is Doable But Poses Methodological Challenges. Journal of Clinical Epidemiology, 72, 10-15. https://doi.org/10.1016/j.jclinepi.2015.10.021

Cao, J., Jiang, Z., \& Wang, K. (2016). Customer Demand Prediction of Service-Oriented Manufacturing Incorporating Customer Satisfaction. International Journal of Production Research, 54, 1303-1321. https://doi.org/10.1080/00207543.2015.1067377

Carlton, E. L., \& Singh, S. R. (2018). Joint Community Health Needs Assessments as a Path for Coordinating Community-Wide Health Improvement Efforts between Hospitals and Local Health Departments. American Journal of Public Health, 108, 676-682. https://doi.org/10.2105/AJPH.2018.304339

Carter, N., Bryant-Lukosius, D., DiCenso, A., Blythe, J., \& Neville, A. J. (2014). The Use of Triangulation in Qualitative Research. Oncology Nursing Forum, 41, 545-547. https://doi.org/10.1188/14.ONF.545-547

Castleberry, A. (2014). NVivo 10. Version 10. American Journal of Pharmaceutical Education, 78, 25. https://doi.org/10.5688/ajpe78125

CMS Centers for Medicare \& Medicaid Services (2014). HCAHPS: Patients' Perspectives of Care Survey.

http://www.cms.gov/Medicare/Quality-Inititives-Patient-Assessment-Instruments/Hos pital Quality Inits/HospitalHCAHPS.html

CMS Centers for Medicare \& Medicaid Services (2015). The HCAHPS Survey-Frequently Asked Questions. http://www.cms.gov

Comi, A., Bischof, N., \& Eppler, M. J. (2014). Beyond Projection: Using Collaborative Visualization to Conduct Qualitative Interviews. Qualitative Research in Organizations and Management, 9, 110-133. https://doi.org/10.1108/QROM-05-2012-1074

Costanza, D. P., \& Finkelstein, L. M. (2015). Generationally Based Differences in the Workplace: Is There a There There? Industrial and Organizational Psychology, 8, 308-323. https://doi.org/10.1017/iop.2015.15

Dağhan, G., \& Akkoyunlu, B. (2014). A Qualitative Study about Performance Based Assessment Methods Used in Information Technologies Lesson. Educational Sciences: Theory \& Practice, 14, 333-338. https://doi.org/10.12738/estp.2014.1.2005

Dainty, K. N., \& Sinclair, D. (2016). A Critical Qualitative Study of the Position of Middle Managers in Health Care Quality Improvement. Journal of Nursing Care Quality, 32, 172-179. https://doi.org/10.1097/NCQ.0000000000000224

Davenport, T. O. (2015). How HR Plays Its Role in Leadership Development. Strategic HR Review, 14, 89-93. https://doi.org/10.1108/SHR-04-2015-0033

Delmas, M. A., \& Gergaud, O. (2014). Sustainable Certification for Future Generations the Case of Family Business. Family Business Review, 27, 228-243.

https://doi.org/10.1177/0894486514538651

Dick, A. S., \& Basu, K. (1994). Customer Loyalty: Toward an Integrated Conceptual Framework. Journal of the Academy of Marketing Science, 22, 99-113. https://doi.org/10.1177/0092070394222001 
Dupree, J. M., Neimeyer, J., \& Mchugh, M. (2014). An Advanced Look at Surgical Performance under Medicares Hospital-Inpatient Value-Based Purchasing Program: Who Is Winning and Who Is Losing? Journal of the American College of Surgeons, 218, 1-7. https://doi.org/10.1016/j.jamcollsurg.2013.09.017

Eklof, M., \& Ahlborg Jr., G. (2016). Improving Communication among Healthcare Workers: A Controlled Study. Journal of Workplace Learning, 28, 81-96. https://doi.org/10.1108/JWL-06-2015-0050

Engle, R. L., Lopez, E. R., Gormley, K. E., Chan, J. A., Charns, M. P., \& Lukas, C. V. (2017). What Roles Do Middle Managers Play in Implementation of Innovative Practices? Health Care Management Review, 42, 14-27. https://doi.org/10.1097/HMR.0000000000000090

Ferrand, Y. B., Siemens, J., Weathers, D., Frendendall, L. D., Yunsik, C., Pirrallo, R. G., \& Bitner, M. (2016). Patient Satisfaction with Healthcare Services: A Critical Review. Quality Management Journal, 23, 6-22. https://asq.org https://doi.org/10.1080/10686967.2016.11918486

Fleiszer, A. R., Semenic, S. E., Ritchie, J. A., Richer, M., \& Jean-Louis, D. (2015). An Organizational Perspective on the Long-Term Sustainability of a Nursing Best Practice Guidelines Program: A Case Study. BMC Health Services Research, 15, 2-16. https://doi.org/10.1186/s12913-015-1192-6

Fusch, P. I., \& Ness, L. R. (2015). Are We There Yet? Data Saturation in Qualitative Research. The Qualitative Report, 20, 1408-1416. https://nsuworks.nova.edu/tqr/

Gibbons, K. B. (2015). Small Seasonal Business Strategies to Increase Profits through Community Collaboration. Doctoral Dissertation. https://scholarworks.waldenu.edu

Harvey, L. (2015). Beyond Member-Checking: A Dialogic Approach to the Research Interview. International Journal of Research \& Method in Education, 38, 23-38. https://doi.org/10.1080/1743727X.2014.914487

Hermanson, P. M., Berkshire, S. D., Leaming, L., \& Piland, N. (2013). Retail Health Clinics: Sustain or Close? A Case Study. Journal of Management Policy and Practice, 14, 37-41. http://www.na-businesspress.com

Holton, J. A., \& Grandy, G. (2016). Voiced Inner Dialogue as Relational Reflection-on-Action: The Case of Middle Managers in Health Care. Management Learning, 47, 369-390. https://doi.org/10.1177/1350507616629602

Hopper, A. M., \& Uriyo, M. (2015). Using Sentiment Analysis to Review Patient Satisfaction Data Located on the Internet. Journal of Health Organization and Management, 29, 221-233. https://doi.org/10.1108/JHOM-12-2011-0129

Houghton, C., Casey, D., Shaw, D., \& Murphy, K. (2013). Rigor in Qualitative Case Study Research. Nurse Researcher, 20, 12-17. https://doi.org/10.7748/nr2013.03.20.4.12.e326

Iannuzzi, J. C., Kahn, S. A., Zhang, L., Gestring, M. L., Noyes, K., \& Monson, J. R. (2015). Getting Satisfaction: Drivers of Surgical Hospital Consumer Assessment of Health Care Providers And Systems Survey Scores. Journal of Surgical Research, 197, 155-161. https://doi.org/10.1016/j.jss.2015.03.045

Jacob, S. A., \& Furgerson, S. P. (2012). Writing Interview Protocols and Conducting Interviews: Tips for Students New to the Field of Qualitative Research. The Qualitative Report, 17, 1-10. https://nsuworks.nova.edu/tqr/

Klopotan, I., Vrhovec-Zohar, K., \& Mahic, E. (2016). Impact of Income on Customers' Loyalty: Are Customers with Higher Income More Loyal? Business Systems Research, 7, 81-88. https://doi.org/10.1515/bsrj-2016-0006

Koopman, O. (2015). Phenomenology as a Potential Methodology for Subjective Know- 
ing in Science Education Research. Indo-Pacific Journal of Phenomenology, 15, 1-10.

https://www.nisc.co.za

https://doi.org/10.1080/20797222.2015.1049898

Kotler, P. (2015). The Founding Father. In Conversations with Marketing Masters (pp. 6-23). Berlin: Springer.

Kotula, M., Ho, W., Dey, P. K., \& Lee, C. K. (2015). Strategic Sourcing Supplier Selection Misalignment with Critical Success Factors: Findings from Multiple Case Studies in Germany and the United Kingdom. International Journal of Production Economics, 166, 238-247. https://doi.org/10.1016/j.ijpe.2014.12.039

Lariviere, B., Keiningham, T. L., Cooil, B., Aksoy, L., \& Malthouse, E. C. (2014). A Longitudinal Examination of Customer Commitment and Loyalty. Journal of Service Management, 25, 75-100. https://doi.org/10.1108/JOSM-01-2013-0025

Leedy, P. D., \& Ormrod, J. E. (2013). Practical Research: Planning Design (10th ed.). Upper Saddle River, NJ: Pearson Education.

Loewenson, R., \& Simpson, S. (2017). Strengthening Integrated Care through Population-Focused Primary Care Services: International Experiences outside the United States. Annual Review of Public Health, 38, 413-429. https://doi.org/10.1146/annurev-publhealth-031816-044518

Lokdam, N., Kristiansen, M., Handlos, L. N., \& Norredam, M. (2016). Use of Healthcare Services in the Region of Origin among Patients with an Immigrant Background in Denmark: A Qualitative Study of the Motives. BMC Health Services Research, 16, 1-10. https://doi.org/10.1186/s12913-016-1346-1

Marais, H. (2012). A Multi-Methodological Framework for the Design and Evaluation of Complex Research Projects and Reports in Business and Management Studies. Electronic Journal of Business Research Methods, 10, 64-76.

http://www.ejbrm.com/main.html

Marshall, B., Cardon, P., Poddar, A., \& Fontenot, R. (2013). Does Sample Size Matter in Qualitative Research: A Review of Qualitative Interviews in IS Research. Journal of Computer Information Systems, 54, 11-22. https://doi.org/10.1080/08874417.2013.11645667

Marshall, C., \& Rossman, G. B. (2016). Designing Qualitative Research (6th ed.). Thousand Oaks, CA: Sage.

Mehra, P. (2016). Outpatient Clinic Waiting Time, Provider Communication Styles and Satisfaction with Healthcare in India. International Journal of Health Care Quality Assurance, 29, 759-777. https://doi.org/10.1108/IJHCQA-02-2016-0017

Mercieca, C., Cassar, S., \& Borg, A. A. (2014). Listening to Patients: Improving the Outpatient Service. International Journal of Healthcare Quality Assurance, 27, 44-53. https://doi.org/10.1108/IJHCQA-03-2012-0033

Merriam, S. B., \& Tisdell, E. J. (2015). Qualitative Research: A Guide to Design and Implementation. San Francisco, CA: Wiley.

Mohebifar, R., Hasani, H., Barikani, A., \& Rafiei, S. (2016). Evaluating Service Quality from Patients' Perceptions: Application of Importance-Performance Analysis Method. Osong Public Health and Research Perspectives, 7, 233-238. https://doi.org/10.1016/j.phrp.2016.05.002

Morse, J. M. (2015). Critical Analysis of Strategies for Determining Rigor in Qualitative Inquiry. Qualitative Health Research, 25, 1212-1222. https://doi.org/10.1177/1049732315588501

Munn, Z., Porritt, K., Lockwood, C., Aromataris, E., \& Pearson, A. (2014). Establishing 
Confidence in the Output of Qualitative Research Synthesis: The ConQual Approach. BMC Medical Research Methodology, 14, 1-7. https://doi.org/10.1186/1471-2288-14-108

Newman, I., \& Benz, C. R. (2006). Qualitative-Quantitative Research Methodology: EXploring the Interactive Continuum. Carbondale, IL: Southern Illinois University Press.

Nicol, E. D., Mohanna, K., \& Cowpe, J. (2014). Perspectives on Clinical Leadership: A Qualitative Study Exploring the Views of Senior Health Care Leaders in the UK. Journal of the Royal Society of Medicine, 107, 277-286.

https://doi.org/10.1177/0141076814527274

Noble, H., \& Smith, J. (2015). Issues of Validity and Reliability in Qualitative Research. Evidence Based Nursing, 18, 34-35. https://doi.org/10.1136/eb-2015-102054

Oldenhof, L., Stoopendaal, A., \& Putters, K. (2016). Professional Talk: How Middle Managers Frame Care Workers as Professionals. Health Care Analysis, 24, 47-70. https://doi.org/10.1007/s10728-013-0269-9

Palinkas, L. A., Horwitz, S. M., Green, C. A., Wisdom, J. P., Duan, N., \& Hoagwood, K. (2013). Purposeful Sampling for Qualitative Data Collection and Analysis in Mixed Method Implementation Research. Administration and Policy in Mental Health and Mental Health Services Research, 42, 533-544. https://doi.org/10.1007/s10488-013-0528-y

Pflueger, D. (2016). Knowing Patients: The Customer Survey and the Changing Margins of Accounting in Healthcare. Accounting, Organizations and Society, 53, 17-33. https://doi.org/10.1016/j.aos.2016.08.002

Platonova, E. A., Qu, H., \& Warren-Findlow, J. (2019). Patient-Centered Communication: Dissecting Provider Communication. International Journal of Health Care Quality Assurance, 32, 534-546. https://doi.org/10.1108/IJHCQA-02-2018-0027

Prakash, G. (2015). Steering Healthcare Service Delivery: A Regulatory Perspective. International Journal of Health Care Quality Assurance, 28, 173-192.

https://doi.org/10.1108/IJHCQA-03-2014-0036

Qayyum, Z. U. (2015). Image Retrieval through Qualitative Representations over Semantic Features. Multimedia Tools and Applications, 74, 1935-1959.

https://doi.org/10.1007/s11042-013-1731-2

Ranney, M. L., Meisel, Z. F., Choo, E. K., Garro, A. C., Sasson, C., Gutrie, K. M., \& Arthur, N. (2015). Interview-Based Qualitative Research in Emergency Care Part II: Data Collection, Analysis and Results Reporting. Society for Academic Emergency Medicine, 22, 1103-1112. https://doi.org/10.1111/acem.12735

Research Triangle Institute International (2016). Delivering the Promise of Science for Global Good. https://www.rti.org/

Rowley, J. (2012). Conducting Research Interviews. Management Research Review, 35, 260-271. https://doi.org/10.1108/01409171211210154

Saadat, M., Panah, A. D., \& Noroozi, F. (2017). Evaluating Relationship between the Implementation of Healthcare Reform and Patient Satisfaction in Health Care Centers of Yasuj. World Family Medicine Journal/Middle East Journal of Family Medicine, 15, 157-161. https://doi.org/10.5742/MEWFM.2017.93155

Sahin Dölarslan, E. (2014). Assessing the Effects of Satisfaction and Value on Customer Loyalty behaviors in Service Environments. Management Research Review, 37, 706-727. https://doi.org/10.1108/MRR-06-2013-0152

Sandelowski, M. (2015). A Matter of Taste: Evaluating the Quality of Qualitative Research. 
Nursing Inquiry, 22, 86-94. https://doi.org/10.1111/nin.12080

Sarma, S. K. (2015). Qualitative Research: Examining the Misconceptions. South Asian Journal of Management, 22, 176-191.

Schaufeli, W. B. (2015). Engaging Leadership in the Job Demands-Resources Model. Career Development International, 20, 446-463. https://doi.org/10.1108/CDI-02-2015-0025

Schiff, G. D., Nieva, H. R., Griswold, P., Leydon, N., Ling, J., Biondolillo, M., \& Singer, S. J. (2016). Addressing Ambulatory Safety and Malpractice: The Massachusetts PROMISES Project. Health Services Research, 51, 2634-2641. https://doi.org/10.1111/1475-6773.12621

Simon, M. K., \& Goes, J. (2013). Dissertation and Scholarly Research: Recipes for Success. Seattle, WA: Create Space Independent Publishing Platform.

Skinner, D. (2014). Health Care and the Disembodied Politics of American Liberalism. Studies in Law, Politics and Society, 65, 107-136. https://doi.org/10.1108/S1059-433720140000065004

Srivastava, M., \& Rai, A. K. (2014). An Investigation into Service Quality-Customer Loyalty Relationship: The Moderating Influences. Decision, 41, 11-31. https://doi.org/10.1007/s40622-014-0025-5

Stake, R. E. (2010). The Art of Case Study Research. Thousand Oaks, CA: Sage.

Starik, M., \& Kanashiro, P. (2013). Toward a Theory of Sustainability Management: Uncovering and Integrating the Nearly Obvious. Organization \& Environment, 26, 7-30. https://doi.org/10.1177/1086026612474958

Steinmeier, M. (2016). Fraud in Sustainability Departments? An Exploratory Study. Journal of Business Ethics, 138, 477-492. https://doi.org/10.1007/s10551-015-2615-3

Stivala, A. D., Koskinen, J. H., Rolls, D. A., Wang, P., \& Robins, G. L. (2016). Snowball Sampling for Estimating Exponential Random Graph Models for Large Networks. Social Networks, 47, 167-188. https://doi.org/10.1016/j.socnet.2015.11.003

Stock, R. M., \& Bednarek, M. (2014). As They Sow, So Shall They Reap: Customers' Influence on Customer Satisfaction at the Customer Interface. Academy of Marketing Science Journal, 42, 400-414. https://doi.org/10.1007/s11747-013-0355-4

Strauss, A., \& Corbin, J. (2015). Basics of Qualitative Research: Techniques and Procedures for Developing Grounded Theory. Thousand Oaks, CA: Sage.

Suri, H. (2011). Purposeful Sampling in Qualitative Research Synthesis. Qualitative Research Journal, 11, 63-75. https://doi.org/10.3316/QRJ1102063

Tam, N. T., Huy, N. T., Thoa, L. T. B., Long, N. P., Trang, N. T. H., Hirayama, K., \& Karbwang, J. (2015). Participants' Understanding of Informed Consent in Clinical Trials over Three Decades: Systematic Review and meta-Analysis. Bulletin of the World Health Organization, 93, 186-198. https://doi.org/10.2471/BLT.14.141390

Wells, M., Semple, C. J., \& Lane, C. (2015). A National Survey of Healthcare Professionals Views on Models of Follow up, Holistic Needs Assessment and Survivorship Care for Patients with Head and Neck Cancer. European Journal of Cancer Care, 24, 873-883. https://doi.org/10.1111/ecc.12285

Woods, M., Paulus, T., Atkins, D. P., \& Macklin, R. (2016). Advancing Qualitative Research Using Qualitative Data Analysis Software (QDAS)? Reviewing Potential versus Practice in Published Studies Using ATLAS.ti and NVivo, 1994-2013. Social Science Computer Review, 34, 597-617. https://doi.org/10.1177/0894439315596311

Wright, W. L. (2017). New Hampshire Nurse Practitioners Take the Lead in Forming an 
Accountable Care Organization. Nursing Administration Quarterly, 4, 39-47. https://doi.org/10.1097/NAQ.0000000000000205

Wyness, L., Jones, P., \& Klapper, R. (2015). Sustainability: What the Entrepreneurship Educators Think. Education \& Training, 57, 834-852.

https://doi.org/10.1108/ET-03-2015-0019

Yin, R. (2017). Case Study Research: Design and Methods (6th ed.). Thousand Oaks, CA: Sage. 